\title{
A Novel Extracellular Calcium Sensing Mechanism in Voltage-Gated Potassium Ion Channels
}

\author{
J. P. Johnson Jr, Jeffrey R. Balser, and Paul B. Bennett \\ Department of Pharmacology, Vanderbilt University School of Medicine, Nashville, Tennessee 37232-6602
}

Potassium $\left(\mathrm{K}^{+}\right)$channels influence neurotransmitter release, burst firing rate activity, pacing, and critical dampening of neuronal circuits. Internal and external factors that further modify $\mathrm{K}^{+}$channel function permit fine-tuning of neuronal circuits. Human ether-à-go-go-related gene (HERG) $\mathrm{K}^{+}$channels are unusually sensitive to external calcium concentration $\left(\left[\mathrm{Ca}^{2+}\right]_{0}\right)$. Small changes in $\left[\mathrm{Ca}^{2+}\right]_{0}$ shift the voltage dependence of channel activation to more positive membrane potentials, an effect that cannot be explained by nonspecific surface charge screening or channel pore block. The HERG-calcium concentration-response relationship spans the physiological range for $\left[\mathrm{Ca}^{2+}\right]_{0}$. The modulatory actions of calcium are attributable to differences in the $\mathrm{Ca}^{2+}$ affinity between rested and activated channels. Adjacent extracellular, negatively charged amino ac- ids (E518 and E519) near the S4 voltage sensor influence both channel gating and $\mathrm{Ca}^{2+}$ dependence. Neutralization of these charges had distinct effects on channel gating and calcium sensitivity. A change in the degree of energetic coupling between these amino acids on transition from closed to activated channel states reveals movement in this region during channel gating and defines a molecular mechanism for protein statedependent ligand interactions. The results suggest a novel extracellular $\left[\mathrm{Ca}^{2+}\right]_{\mathrm{o}}$ sensing mechanism coupled to allosteric changes in channel gating and a mechanism for fine-tuning cell repolarization.

Key words: human ether-à-go-go-related gene; potassium channel gating; HERG; calcium; allosteric; Monod-WymanChangeux
Plasticity and adaptive behavior in circuits of the nervous system depend on the dynamic properties of ion channels. Potassium channels modulate neuronal excitability and, in turn, are modulated by both intracellular and extracellular factors. The human ether-à-go-go-related gene (HERG) potassium channel has recently been discovered to play important roles in excitable tissues. Originally identified in hippocampus (Warmke and Ganetzky, 1994), HERG channels also play a role in myocardial repolarization (Sanguinetti et al., 1995). ERG channels have been implicated in neural crest cell development (Arcangeli et al., 1997), neoplastic cell survival (Bianchi et al., 1998), and neural spike frequency adaptation (Chiesa et al., 1997). Furthermore, the Drosophila erg is encoded at the seizure locus, originally defined by temperature-sensitive paralytic mutations in flies (Titus et al., 1997; X. J. Wang et al., 1997).

HERG channels (Warmke and Ganetzky, 1994; Trudeau et al., $1995)$ are six transmembrane (6 TM) family voltage-gated potassium channels and contain the typical motifs identified in these channels (S5-P-loop-S6, charged S4 voltage sensor, etc.). Unlike many other $6 \mathrm{TM} \mathrm{K}^{+}$channels (Drosophila Shaker, Shal, Shab, Shaw, vertebrate Kv channels), HERG channels are highly sensitive to modest changes in extracellular divalent cation concentrations (Ho et al., 1998; Johnson et al., 1999; Po et al., 1999) around the physiological set point (1-3 mM). This sensitivity is much greater and qualitatively distinct from that in other voltage-

\footnotetext{
Received Dec. 21, 2000; revised March 19, 2001; accepted March 22, 2001.

This work was supported by National Institutes of Health Grants T32 HL07411, T32 GM07628, HL 51197, and HL 46681. We thank Drs. Louis J. DeFelice and Christoph Fahlke for their insightful discussions and Dr. Christoph Fahlke for critical reading of this manuscript.

Correspondence should be addressed to Dr. Paul B. Bennett, Senior Director, Ion Channel Research, W P42-209 (Pharmacology), Merck Research Laboratories, 770 Sumneytown Pike, West Point, PA 19486. E-mail: paul_bennett@merck.com. Copyright (C) 2001 Society for Neuroscience $0270-6474 / 01 / 214143-11 \$ 15.00 / 0$
}

gated delayed rectifier potassium channels (Frankenhaeuser and Hodgkin, 1957; Gilly and Armstrong, 1982; Johnson et al., 1999; Po et al., 1999) and cannot be explained by nonspecific surface charge screening or pore block. Changes in extracellular $\mathrm{Ca}^{2+}$ appear to discretely modify the voltage dependence of activation of HERG with little effect on channel inactivation (Johnson et al., 1999), suggesting that the voltage dependence of HERG K${ }^{+}$ channel inactivation is distinct from the voltage dependence of activation gating as noted before (Spector et al., 1996; S. Wang et al., 1996, 1997; J. Wang et al., 1998; Zou et al., 1998). This specific interaction with one aspect of channel gating is intriguing and suggests interactions of $\mathrm{Ca}^{2+}$ with amino acids in regions of the channel involved in the voltage dependence of channel opening.

Interestingly, there are two nonconserved negatively charged amino acids (glutamic acids) located in the HERG extracellular loop between S3 and S4. These extracellular facing negative charges are immediately adjacent to the $\mathrm{S} 4$ voltage sensor and are good candidates for an interaction with $\mathrm{Ca}^{2+}$ or with some of the positive charges in the $\mathrm{S} 4$, leading to $\mathrm{Ca}^{2+}$ titratable changes in gating. The purpose of this investigation was to develop a better understanding of the molecular basis of modifications of HERG function by $\mathrm{Ca}^{2+}$ through analysis of the gating and $\left[\mathrm{Ca}^{2+}\right]_{\mathrm{o}}$ interactions in wild-type (WT) and HERG mutant channels in which these negative charges were neutralized.

\section{MATERIALS AND METHODS}

cDNA constructs and site-directed mutagenesis. The human ether-à-go-gorelated gene $(H E R G)$ cDNA was obtained from Dr. Mark Keating (University of Utah) and ligated into the pSI mammalian expression plasmid (Promega, Madison, WI). Dr. Richard Horn (Jefferson Medical College) kindly provided the CD8 antigen gene in the EBO-pcD Leu2 vector. CD8, a human $\mathrm{T}$ lymphocyte surface antigen, was cotransfected with the channel construct to allow visual identification of transfected cells (Jurman et al., 1994). Mutagenesis was performed by the overlapextension recombinant PCR technique using VENT ${ }^{\circledR}$ DNA polymerase 
(New England Biolabs, Beverly, MA). All constructs were assembled in the HERG pSI construct. Briefly, two separate PCR reactions were performed to generate overlapping products containing a desired point mutation in the overlap region. The first round PCR products were purified with QIAQuick purification columns (Qiagen, Hilden, Germany) to remove primers, and the two products were denatured and annealed to one another. Finally, the complete region was amplified in a second round of PCR with a nested set of primers. The PCR cassette was digested then and subcloned into the full-length cDNA using flanking restriction sites. Multiple clones were selected and analyzed by restriction digestion, and DNA sequencing of the entire region was amplified by PCR. For each mutant, two independent correctly assembled and fully sequenced clones were tested electrophysiologically.

Electrophysiology and solutions. HERG channel function was studied with the whole-cell patch-clamp technique by methods identical to those in Johnson et al. (1999). Cells were patch clamped 36-60 hr after transfection, and all experiments were performed at room temperature $\left(23-25^{\circ} \mathrm{C}\right)$. The intracellular recording solution for all experiments contained (in mM): $110 \mathrm{KCl}, 5 \mathrm{~K}_{2} \mathrm{ATP}, 5 \mathrm{~K}_{4}$ BAPTA, $2 \mathrm{MgCl}_{2}, 10 \mathrm{HEPES}$, $\mathrm{pH}$ 7.2. The extracellular recording solution used for the experiments in Figure $1 A$ contained (in mM): $145 \mathrm{NaCl}, 4 \mathrm{KCl}, 1.8 \mathrm{CaCl}_{2}, 1 \mathrm{MgCl}_{2}, 10$ HEPES, 10 glucose, $\mathrm{pH}$ 7.35. The base extracellular solution for all other figures contained (in mM): $145 \mathrm{NaCl}, 4 \mathrm{KCl}, 10 \mathrm{HEPES}, 10$ glucose. For solutions of $\mathrm{Ca}^{2+}$ concentrations from $100 \mu \mathrm{M}$ to $10 \mathrm{~mm}$, the appropriate amount of $1 \mathrm{M} \mathrm{CaCl}_{2}$ was added to a $2 \times$ concentrated form of the above base solution before addition of $\mathrm{NaOH}$ to bring the $\mathrm{pH}$ to 7.35 and the final dilution to $1 \times$ with deionized water. For $\mathrm{Ca}^{2+}$ concentrations from 3 to $30 \mu \mathrm{M}, 1 \mathrm{~mm}$ H-ethylenediamine- $N, N^{\prime}, N^{\prime}$-triacetic acid was added to the base solution to buffer the $\mathrm{Ca}^{2+}$ concentration. The free $\mathrm{Ca}^{2+}$ concentrations were calculated assuming $25 \mu \mathrm{M}$ contaminant $\mathrm{Ca}^{2+}$ using MaxChelator Sliders version 1.0 software (Chris Patton, Stanford University, www.stanford.edu/ cpatton/maxc.html) using the Martell and Smith constants.

In figures with raw data, the zero current level is indicated by the bottom of the current calibration bar (vertical) in each figure. Leak correction was not used in any of the raw current traces shown. In a few cases, moderate linear leak correction was used offline using Clampfit. Cell capacitance and series resistance were compensated using the analog controls on the Axopatch 200.

Chinese hamster ovary K1 (CHO-K1) cells were obtained from the American Type Culture Collection (Rockville, MD) and maintained in HAMS F-12 media (Life Technologies, Grand Island, NY) supplemented with $1 \mathrm{~mm}$ L-glutamine and $10 \%$ heat-inactivated fetal bovine serum (Life Technologies) in a humidified, $5 \% \mathrm{CO}_{2}$ incubator at $37^{\circ} \mathrm{C}$. CHO-K1 cells were cotransfected with the $H E R G$ and CD8 plasmids in a ratio of 4:1. Transfection was accomplished using the Lipofectamine transfection reagents and method (Life Technologies).

Data analysis. Data were analyzed and plotted using pClamp 6.03, Origin 5.0 (Microcal Software, Northhampton, MA), SigmaPlot 4.0 (SPSS Inc., Chicago, IL), and TableCurve 3D 3.0 (SPSS Inc.) software. The midpoints $\left(V_{1 / 2}\right)$ of channel activation were determined by fitting the data with a Boltzmann function of the form:

$$
I / I_{\text {Max }}=1 /\left(1+\exp \left(\left[V-V_{1 / 2}\right] / k_{\mathrm{v}}\right),\right.
$$

where $I_{\mathrm{Max}}$ is the limiting amplitude, $V_{1 / 2}$ is the membrane potential where $I / I_{\mathrm{Max}}=0.5$, and $k_{\mathrm{v}}$ is the slope factor. Concentration-effect data were fit with the Hill equation:

$$
I / I_{\mathrm{Max}}=y_{0}+\left(A\left[\mathrm{Ca}^{2+}\right]^{\mathrm{b}}\right) /\left(\left(K_{\mathrm{D}}\right)^{\mathrm{b}}+\left[\mathrm{Ca}^{2+}\right]^{\mathrm{b}}\right),
$$

where $I$ is current, $I_{\mathrm{Max}}$ is the maximal current, $y_{0}$ is the current at a given voltage in the absence of $\mathrm{Ca}^{2+}, A$ is an amplitude term, $K_{\mathrm{D}}$ is the apparent $\mathrm{Ca}^{2+}$ dissociation constant, and $b$ is the Hill coefficient.

A voltage-dependent Monod-Wyman-Changeux (MWC) model of allosteric protein function (Monod et al., 1965; Galzi et al., 1996; Cox et al., 1997; Changeux and Edelstein, 1998) was used to analyze the data. The model is described by Equation 3 below:

$$
G / G_{\mathrm{Max}}=\frac{1}{1+\left[\frac{1+\frac{\left[\mathrm{Ca}^{2+}\right]}{K c}}{1+\frac{\left[\mathrm{Ca}^{2+}\right]}{K a}}\right]^{4} L_{0} e^{-(Q F V / R T)}} .
$$

$F$ is the Faraday constant in coulombs per mole; $T$ is temperature in degrees Kelvin; $R$ is the gas constant in Joules per degree (Kelvin) per mole. $V$ is membrane potential (volts). There are four free parameters in the equation: $Q, K c, K a$, and $L_{0}$. The apparent gating charge, $Q$, that moves through the membrane electrical field during the transitions from closed to activated determines the voltage dependence, i.e., the steepness of the sigmoid curves in Figures 4 and $6 . K c$ is the $\mathrm{Ca}^{2+}$ dissociation constant for the closed channel. $\mathrm{Ka}$ is the $\mathrm{Ca}^{2+}$ dissociation constant for the activated (open) channel. The degree of separation between the voltage-dependent activation curves in low and high $\mathrm{Ca}^{2+}$ is determined by the relative affinities of the closed and activated states ( $K c$ and $K a$ ). A large difference between $K c$ and $K a$ results in a larger separation between the voltage-dependent activation curves. $L_{0}$ is the closed-open equilibrium constant in the absence of calcium, and it determines the lower limit of the midpoints of the voltage-dependent activation curves. $L_{0}$ determines the relative position of the family of voltage-dependent activation curves on the voltage axis (see Fig. 4) or the baseline of the $V_{1 / 2}$ versus $\mathrm{Ca}^{2+}$ concentration relationship (see Fig. 5). Global fitting (Balser et al., 1990) of the allosteric MWC model to HERG currents simultaneously across multiple voltages and $\mathrm{Ca}^{2+}$ concentrations was performed with TableCurve 3D software using an iterative 64-bit Levenburg-Marquardt fitting algorithm. It should be noted that although the model is helpful for quantifying and interpreting the effect of the mutations and $\mathrm{Ca}^{2+}$, the primary conclusions are not dependent on the model.

Thermodynamic cycle analysis. Channel alterations that energetically affect ligand binding or gating can be analyzed formally by evaluating the contributions of individual perturbations (Carter et al., 1984; Sali et al., 1991; Hidalgo and MacKinnon, 1995). For example, alterations in binding caused by a mutation can be defined in terms of perturbations in binding energies:

$$
\Delta \Delta G=-R T \ln \left\{K_{\text {mutant }} / K_{\mathrm{WT}}\right\},
$$

where $K_{\text {mutant }}$ and $K_{\mathrm{WT}}$ are the equilibrium binding constants for mutant and wild-type channels, respectively. If different amino acids contribute to the binding but they contribute independently, then altering them should independently affect the outcome. The diagram below illustrates the method used for these calculations:

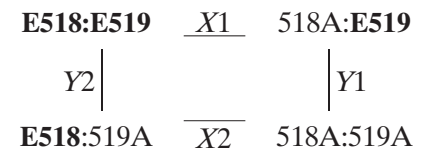

The bold lettering indicates a wild-type residue. The upper left construct is the fully WT channel, and the bottom right is the EEAA double mutant channel. $X 1$ is the dissociation constant for the WT E518:E519 channel divided by that of the single mutant 518A:E519 and represents the change in free energy between the WT and E518A single mutant. $Y 1$ is the dissociation constant for the single mutant 518A:E519 divided by that of the double mutant 518A:519A and reflects the change in free energy between the E518A single mutant and the EEAA double mutant channel. These calculations were then extended to generate $X 2$ and $Y 2$. The null hypothesis is that, if there is no energetic coupling between the two residues, the change in free energy between the WT and EEAA channel will be independent of which residue was mutated first, generating an energetic coupling coefficient $(\boldsymbol{\Omega})$ of unity. $\boldsymbol{\Omega}$ is described by the equation (Carter et al., 1984):

$$
\Omega=X 1 * Y 1=X 2 * Y 2=\frac{K_{\mathrm{D}}(\mathrm{wt}: \mathrm{wt}) * K_{\mathrm{D}}(\text { mut:mut })}{K_{\mathrm{D}}(\mathrm{wt}: \mathrm{mut}) * K_{\mathrm{D}}(\text { mut:wt })} .
$$

In all cases, $\Omega$ values calculated by $X 1 / X 2$ were identical to those calculated by $Y 2 / Y 1$.

\section{RESULTS}

\section{Direct observation of HERG inactivation: effect of extracellular $\mathrm{Ca}^{2+}$ on channel gating}

The HERG $\mathrm{K}^{+}$channel was originally described as an inwardly rectifying channel based on the current-voltage relationship (Trudeau et al., 1995). Subsequent studies indicated that this apparent rectification results from inactivation gating (Schönherr and Heinemann, 1996; Smith et al., 1996; Spector et al., 1996). In this regard, HERG $\mathrm{K}^{+}$channels seemed to be atypical, com- 

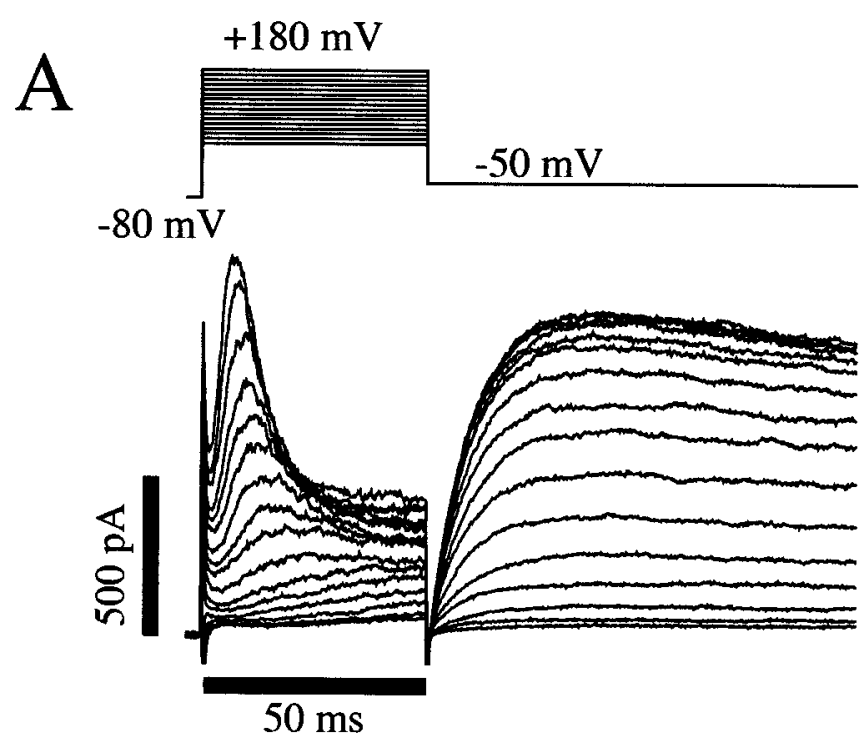

B

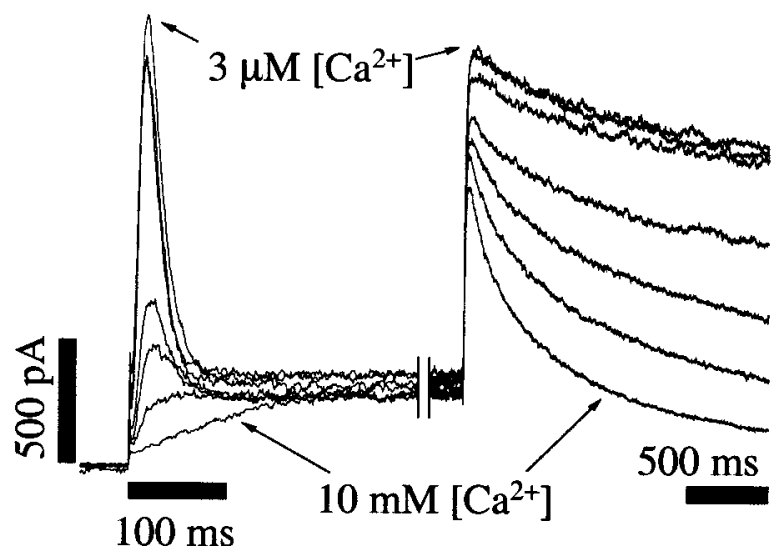

Figure 1. Direct observation of HERG channel inactivation and the effects of $\mathrm{Ca}^{2+}$ to slow the rate of channel activation. $A$, Activation and inactivation of HERG $\mathrm{K}^{+}$currents measured during voltage-clamp steps to membrane potentials between +180 and $+30 \mathrm{mV}$ in $10 \mathrm{mV}$ increments for $50 \mathrm{msec}$ followed by a step to $-50 \mathrm{mV}$ for $100 \mathrm{msec}$. These recordings show rapid activation of HERG $\mathrm{K}^{+}$currents followed by subsequent inactivation resulting in transient outward currents. On stepping to -50 $\mathrm{mV}$, a large slow tail current is observed. The rate of activation (initial rising phase) is highly voltage dependent in this potential range, whereas the inactivation (decay) is not. The membrane potential was held at -80 $\mathrm{mV}$ before and after the test steps. $B$, Increases in the extracellular $\mathrm{Ca}^{2+}$ concentration caused a slowing of channel activation with no effect on inactivation, resulting in a truncation of the peak transient outward currents. The rate of tail current decay at $-50 \mathrm{mV}$ was also increased. Seven $\mathrm{K}^{+}$current traces from the same cell, each in a different extracellular $\left[\mathrm{Ca}^{2+}\right](3 \mu \mathrm{M}, 10 \mu \mathrm{M}, 30 \mu \mathrm{M}, 300 \mu \mathrm{M}, 1 \mathrm{mM}, 3 \mathrm{mM}$, and $10 \mathrm{mM})$, are superimposed. The membrane potential was held at $-80 \mathrm{mV}$ before stepping to $+70 \mathrm{mV}$ for $2 \mathrm{sec}$, then repolarized to $-50 \mathrm{mV}$ to measure tail currents. Note the two time scale bars corresponding to before and after the break in the current record. After $\sim 250 \mathrm{msec}$ at $+70 \mathrm{mV}$, the steady state current level was the same in all $\left[\mathrm{Ca}^{2+}\right]$; even the current in $10 \mathrm{~mm}$ $\mathrm{Ca}^{2+}$ had fully activated.

pared with other six transmembrane family $\mathrm{K}^{+}$channels that are either delayed rectifiers or A-type channels with rapid channel activation followed by somewhat slower inactivation. Figure $1 \mathrm{~A}$ illustrates $\mathrm{HERG} \mathrm{K}^{+}$currents measured during brief $(50 \mathrm{msec})$ steps between +30 and $+180 \mathrm{mV}$. At these membrane potentials, the rate of channel activation became rapid relative to inactivation, and the inactivation process was directly observed. Although the rate of activation remained highly voltage-dependent, the rate of inactivation was nearly constant in this voltage range.

Changes in extracellular $\mathrm{Ca}^{2+}$ modify the voltage dependence of opening of this channel with little effect on channel inactivation (Johnson et al., 1999). Figure $1 B$ demonstrates this directly. Superimposed $\mathrm{K}^{+}$current tracings from a single cell are shown in different extracellular $\mathrm{Ca}^{2+}$ concentrations ranging from $3 \mu \mathrm{M}$ to $10 \mathrm{~mm}$. In the lowest concentrations of $\mathrm{Ca}^{2+}$, the voltage step to $+70 \mathrm{mV}$ elicited a rapidly activating current that quickly inactivated like an A-type $\mathrm{K}^{+}$channel. As extracellular $\mathrm{Ca}^{2+}$ was increased, channel opening was delayed, but the rate of inactivation remained unchanged. The result was a truncation of the observed current peak. Note that marked modulation occurred between 0.3 and $3 \mathrm{~mm}$. The specific interaction of $\mathrm{Ca}^{2+}$ with the voltage dependence of channel activation, but not inactivation, led us to investigate the role of amino acids in the vicinity of the channel voltage sensor in determining channel $\mathrm{Ca}^{2+}$ sensitivity.

\section{Extracellular negatively charged amino acids and the effect of $\left[\mathrm{Ca}^{2+}\right]_{\text {o }}$}

$\mathrm{Ca}^{2+}$ typically interacts with negatively charged amino acid side chains of proteins (Cowan, 1993; Eismann et al., 1994; Schreiber and Salkoff, 1997). This is attributable to the fact that ionized $\mathrm{Ca}^{2+}$ has a full outer electron orbital, giving it a noble gas-like unreactive chemistry. As a result, $\mathrm{Ca}^{2+}$ tends to interact with other molecules largely through electrostatic attraction and repulsion (Cowan, 1993). Likely candidates for $\mathrm{Ca}^{2+}$ interaction are extracellularly exposed negatively charged amino acids such as glutamate and aspartate. Because $\mathrm{Ca}^{2+}$ does not permeate HERG channels and the intracellular solution always contained a high affinity $\mathrm{Ca}^{2+}$ chelator (5 mM BAPTA), the hydrophilic extracellular loops of the channel are candidate regions for $\mathrm{Ca}^{2+}$ interaction. The S4 transmembrane segment has been identified as a voltage sensor of channels in the six transmembrane voltagegated $\mathrm{K}^{+}$channel family (Papazian et al., 1987; Tempel et al., 1987; Perozo et al., 1994; Mannuzzu et al., 1996). The extracellular S3-S4 linker of HERG contains only two acidic amino acids, adjacent glutamates at positions 518 and 519, and they are located just above the S4 transmembrane segment. These negatively charged amino acids were mutated individually and together to probe their role in the response to extracellular $\mathrm{Ca}^{2+}$. The phenotypes of the WT and mutant channels are shown in Figure $2 . \mathrm{K}^{+}$current from cells expressing WT, E518A, E519A, or the double mutant (change of E518 and E519 to alanines: EEAA) are shown at numerous test potentials. Each mutation significantly altered the gating of HERG channels in control extracellular solutions. Interestingly, the E518A mutant appeared very similar to the WT channel in elevated $\left[\mathrm{Ca}^{2+}\right]_{\mathrm{o}}$, e.g., removal of the negative charge caused a decrease in outward current during depolarizations and enhanced the rates of tail current decay. Thus, removal of this negative charge seemed to resemble addition of positive charges $\left(\mathrm{Ca}^{2+}\right)$ in the WT channel. In all three cases (E518A, E519A, and EEAA), outward currents during depolarizations were decreased, and the rates of decay of tail currents were increased. Further evaluation of these mutant channels compared with WT revealed unique differences (described below). First, we evaluated other channel properties to determine whether inactivation or permeation properties were altered. 

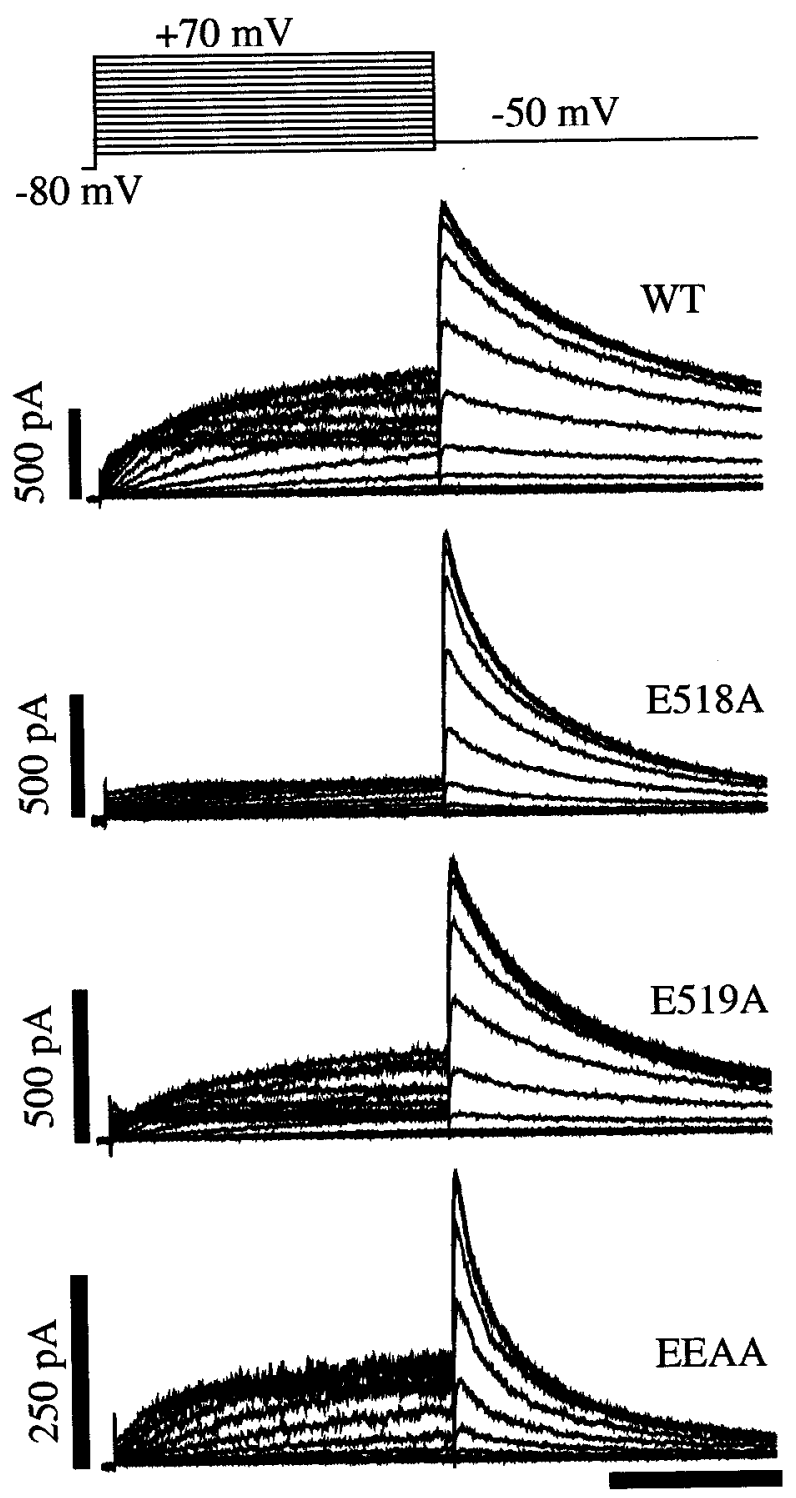

$1 \mathrm{~s}$

Figure 2. Comparison of HERG K ${ }^{+}$currents in WT and S3-S4 charge neutralization mutants. Superimposed families of $\mathrm{K}^{+}$current traces were recorded using the voltage-clamp protocol shown for each channel construct. Cells were held at $-80 \mathrm{mV}$ before stepping to test potentials between +70 and $-60 \mathrm{mV}$ for $2 \mathrm{sec}$. The membrane potential was then stepped to $-50 \mathrm{mV}$ for $2 \mathrm{sec}$ to record tail currents. All records were made in the presence of $3 \mathrm{~mm}$ extracellular $\mathrm{Ca}^{2+}$.

\section{Effect of negatively charged amino acids, mutations, or $\mathrm{Ca}^{2+}$ on inactivation}

Our previous study demonstrated a significant effect of $\mathrm{Ca}^{2+}$ on HERG channel activation gating in the absence of an effect on inactivation (Johnson et al., 1999). Therefore, we wished to determine whether these amino acids that appeared to influence channel activation gating had an effect on channel inactivation. Despite the distinct current phenotypes of the mutant channels, their inactivation was not affected. Neutralization of E518, E519, or both together did not change the HERG channel inactivation time constants measured between 0 and $+100 \mathrm{mV}(p>0.2 ; n=$ 4-8) (Fig. 3). Thus, HERG inactivation gating is insensitive both to external $\mathrm{Ca}^{2+}$ and mutation of E518 and E519, in direct contrast to activation gating.

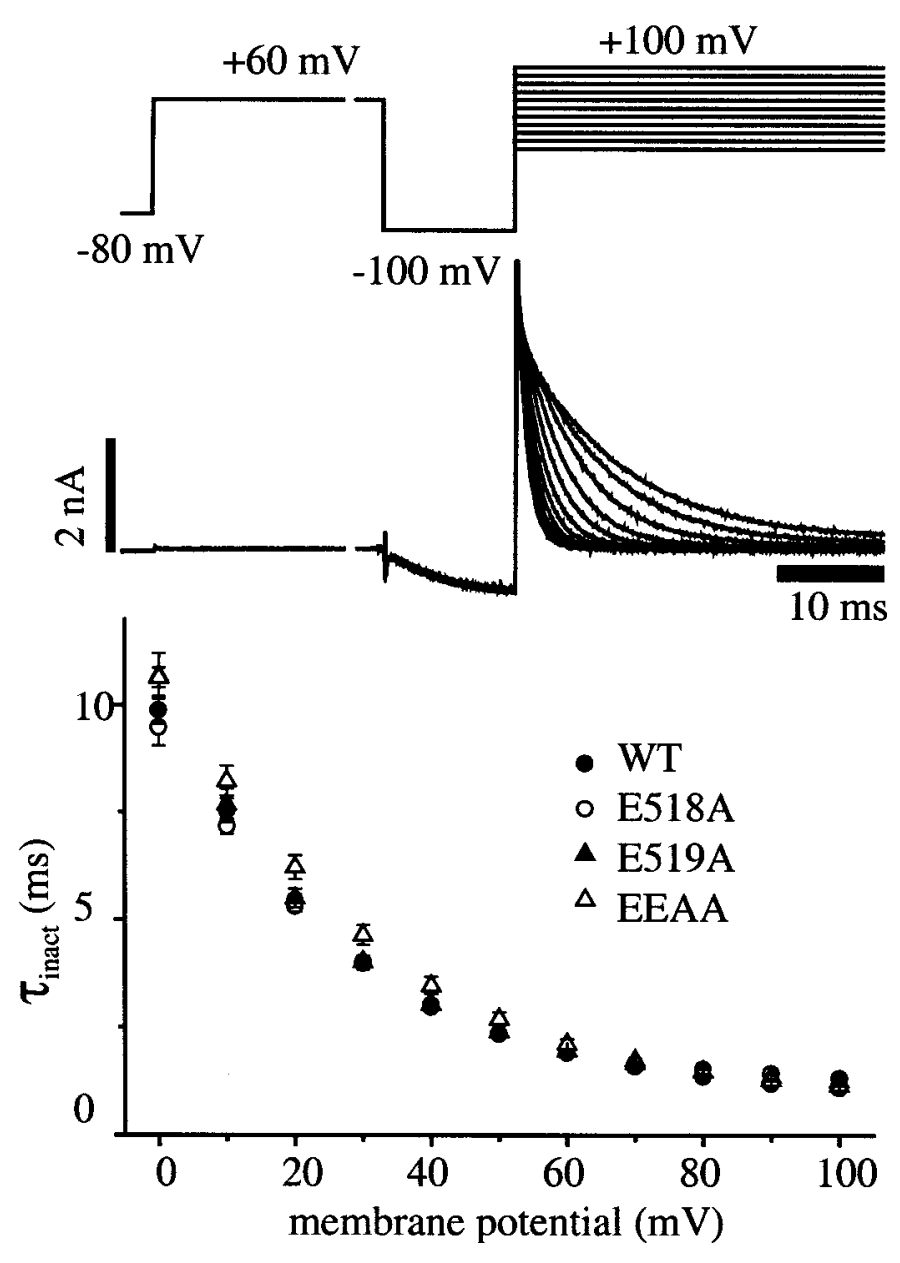

Figure 3. S3-S4 charge neutralization did not affect inactivation. The voltage-clamp protocol is shown at the top. A representative family of current traces is shown in the middle panel. The step to $+60 \mathrm{mV}$ was $2 \mathrm{sec}$ long; the scale bar to the right applies only to the current trace to the right of the break in the record. Time constants were obtained by fitting an exponential function to the decaying current during the third voltage step. Error bars indicate the SEM for $4-8$ cells for each mutant and at each membrane potential.

\section{Mutations did not change $\mathrm{K}^{+}$selectivity}

In contrast to changes in activation gating, we observed no effects on the ion permeation properties, suggesting that other channel properties were not affected by these changes. The ionic selectivity of all the mutant channels was normal, because there was no change in the $\mathrm{K}^{+}$current reversal potential measured in $4 \mathrm{mM}$ extracellular $\mathrm{K}^{+}: \mathrm{WT},-83 \pm 0.9 \mathrm{mV}, n=10$; E518A, $-81 \pm 0.3$ $\mathrm{mV}, n=9$; E519A, $-82 \pm 0.3 \mathrm{mV}, n=10$; EEAA, $-82 \pm 0.6$ $\mathrm{mV}, n=10(\mathrm{NS} ; p>0.2)$.

\section{Effect of negatively charged amino acids or $\mathrm{Ca}^{2+}$ on channel activation}

In Figure 4, voltage-activation curves are shown to compare the shifts in the voltage dependence caused by changes in $\left[\mathrm{Ca}^{2+}\right]_{0}$ in the WT and mutant HERG channels. Increasing $\mathrm{Ca}^{2+}$ caused progressive shifts of channel voltage-dependent activation relationships to more depolarized potentials in all channels, but the magnitude of the $\mathrm{Ca}^{2+}$ response and the relative position of the voltage dependence curves differed among the WT and chargeneutralized mutant channels. Note the differences in degree of separation of the curves in high and low $\mathrm{Ca}^{2+}$ and the relative 


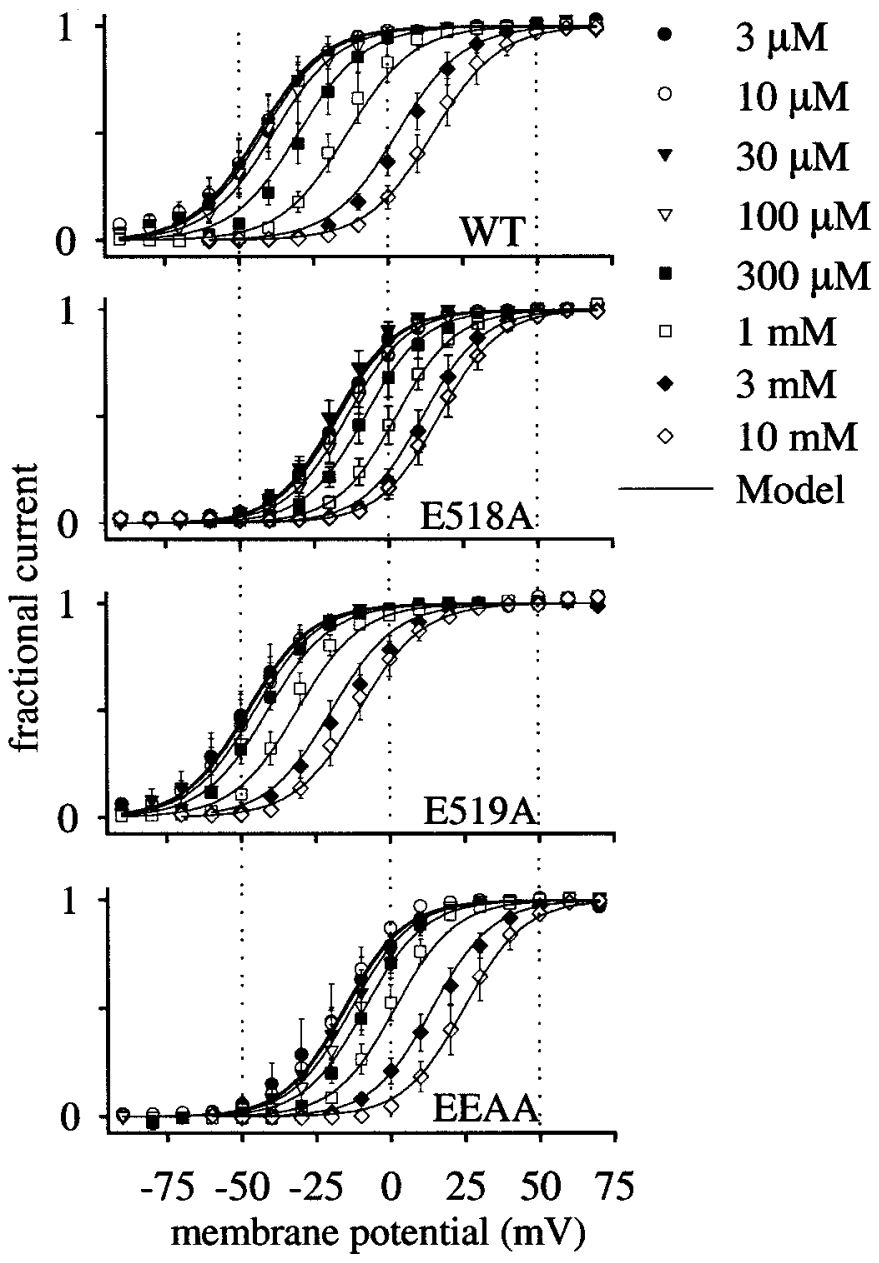

Figure 4. Effect of extracellular $\mathrm{Ca}^{2+}$ on the voltage dependence of activation of WT and mutant HERG channels. Voltage-dependent activation curves were determined from peak tail current amplitudes measured at $-50 \mathrm{mV}$ with a $2 \mathrm{sec}$ step to the test potential (as in Fig. 2). Error bars indicate SEM ( $n=3-15$ for each concentration). Smooth curves correspond to the predicted values based on the three-dimensional fit of the voltage-dependent Monod-Wyman-Changeux model (see Fig. 6, Eq. 3).

shifts caused by change in $\mathrm{Ca}^{2+}$ among the different channels. There did not appear to be changes in the slope of the relationships, but the entire family of curves in a given channel (WT vs each mutant) was variously translated along the voltage axis. The degree to which elevation of $\mathrm{Ca}^{2+}$ was able to shift the curves was different among the channels as well. Initially it seemed paradoxical that channels with such similar and modest changes in amino acid sequence could behave so differently. A channel with the simple removal of a negative charge behaved very differently than when the adjacent charge was neutralized. These distinctions were very nicely accounted for by considering the allosteric nature of the channels. The solid curves through the data were generated by the allosteric gating model described below.

The $\mathrm{Ca}^{2+}$-independent voltage dependence of the channels (i.e., that measured in very low calcium: $3 \mu \mathrm{M} \mathrm{Ca}^{2+}$ ) differed among the channels as well. This can be seen more clearly in Figure 5 in which the half maximal voltages of channel activation

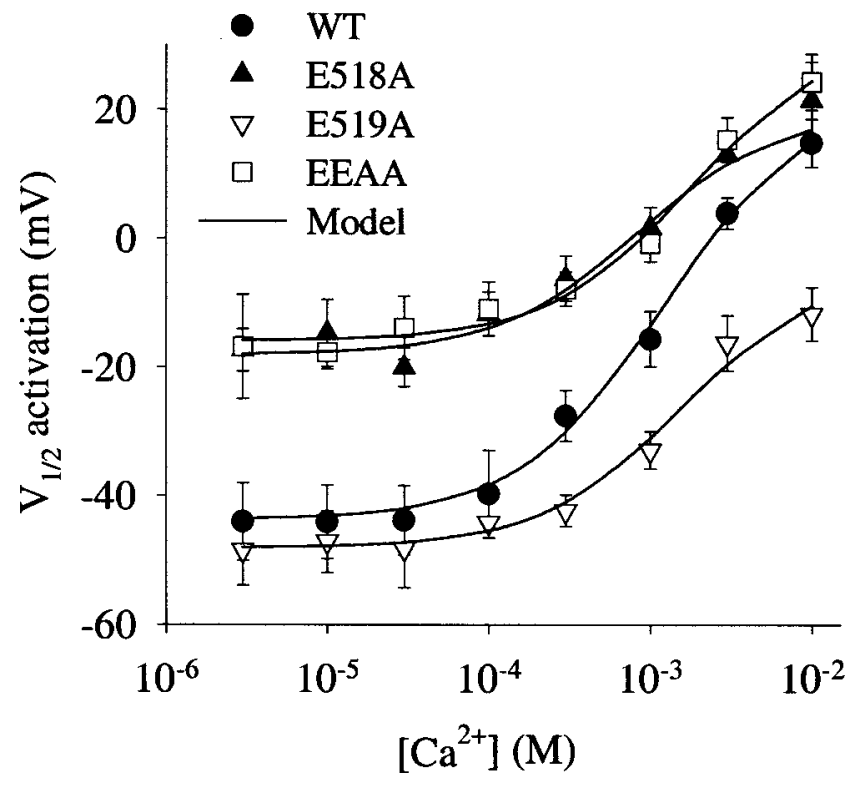

Figure 5. $\mathrm{Ca}^{2+}$ dependence of the half maximal voltage $\left(V_{1 / 2}\right)$ of activation of WT and mutant HERG channels obtained from the curves in Figure 4. Error bars indicate SEM. Smooth curves correspond to the predicted values based on the three-dimensional fit of the voltagedependent Monod-Wyman-Changeux model (see Fig. 6).

$\left(V_{1 / 2}\right)$ measured from data in Figure 4 are plotted as a function of the $\mathrm{Ca}^{2+}$ concentration. The double mutant (EEAA) and the E518A single mutant had a minimal $V_{1 / 2}$ of approximately +30 $\mathrm{mV}$ more depolarized than that of the WT or E519A mutant channels $\left(V_{1 / 2}\right.$ in $3 \mu \mathrm{M}\left[\mathrm{Ca}^{2+}\right]_{\mathrm{o}}$ : WT, $-44 \pm 6 \mathrm{mV}$; E518A, $-17 \pm 3 \mathrm{mV}$; E519A, $-48 \pm 5 \mathrm{mV}$; EEAA, $-17 \pm 8 \mathrm{mV})$. For all channels, the $V_{1 / 2}-\left[\mathrm{Ca}^{2+}\right]$ curve saturated before reaching the lowest tested $\left[\mathrm{Ca}^{2+}\right](3 \mu \mathrm{M})$. Therefore, the minimal $V_{1 / 2}$ can be considered $\mathrm{Ca}^{2+}$ independent. Neutralization of glutamate 518, but not 519, resulted in channels with an altered $\mathrm{Ca}^{2+}$ independent voltage dependence. Channels in which E519 was neutralized had an altered $\mathrm{Ca}^{2+}$ response, but their $\mathrm{Ca}^{2+}$ independent voltage dependence was like that of WT channels.

The $\mathrm{Ca}^{2+}$ responses of the WT and mutant channels for currents measured at membrane potentials between -60 and +30 $\mathrm{mV}$ were fit with a Hill equation (Eq. 2; same data as in Fig. 4 analyzed as a function of $\left[\mathrm{Ca}^{2+}\right]_{\mathrm{o}}$; data not shown). The fitted parameters $\left(K_{\mathrm{D}}\right.$ and Hill coefficient, b) were highly voltage dependent. The Hill coefficients from these fits varied from a minimum near one to a maximum greater than three depending on the membrane potential, suggesting multiple binding sites and cooperativity. Thus, a single $\mathrm{Ca}^{2+}$ binding site seems unlikely for several reasons. First, the Hill coefficient (b $>1$, Eq. 2) values indicate increased complexity and suggest multiple $\mathrm{Ca}^{2+}$ binding sites. Secondly, HERG, like other six transmembrane domain voltage-gated $\mathrm{K}^{+}$channels, is believed to form rotationally symmetric homotetrameric channels when expressed alone in heterologous systems. If all four subunits cooperated to create a single $\mathrm{Ca}^{2+}$ binding site on the extracellular face of the channel, this site would necessarily be centrally located and would therefore likely be in the channel pore. However, we know that $\mathrm{Ca}^{2+}$ does not block HERG channels as would be expected for a binding site in the pore lumen (Johnson et al., 1999). In the absence of a single centrally located $\mathrm{Ca}^{2+}$ binding site, a likely possibility for a homotetrameric channel is that each subunit has its own $\mathrm{Ca}^{2+}$ 
site(s). The similarities to hanatoxin modification of Kv2.1 and omega-Aga-IVA modification of calcium channels are also consistent with four $\mathrm{Ca}^{2+}$ sites and certainly more than one (Swartz and MacKinnon, 1995, 1997a,b; Li-Smerin and Swartz, 1998; Winterfield and Swartz, 2000).

The Hill fit-derived parameters must be interpreted cautiously, and the apparent voltage dependence of the Hill-derived $\mathrm{K}_{\mathrm{D}} \mathrm{s}$ can be interpreted in several ways. First, this nonglobal analysis (i.e., fitting only a single independent variable at a time) neglects relevant information about the system, for example membrane potential. Although the $\mathrm{Ca}^{2+}$ response is obtained at several membrane potentials, each fit is independent and not constrained by data at other membrane potentials. The Hill fit analysis also lumps all interactions (possibly multiple $\mathrm{K}_{\mathrm{D}} \mathrm{s}$ ) into a single $\mathrm{K}_{\mathrm{D}}$. In contrast, the global fit (discussed below) is constrained by information obtained across all membrane potentials and calcium concentrations. The voltage-dependent apparent $\mathrm{K}_{\mathrm{D}}$ values from the Hill fit analysis suggest several possible interpretations. First, the accessibility of the ligand to a single binding site of constant affinity could change as a function of membrane potential, because of the voltage-dependent channel conformational changes that must occur for channel function, i.e., the binding site is partially guarded. This would cause an apparent change in the affinity, but cannot account for the Hill coefficients that differ from unity. Another possible explanation for the voltagedependent $\mathrm{K}_{\mathrm{D}}$ is that $\mathrm{Ca}^{2+}$ binding is influenced by the electric field through a direct effect on the positively charged ligand. In the Hill equation analysis, the fitted $\mathrm{K}_{\mathrm{D}} \mathrm{s}$ ranged from $\leq 10^{-4} \mathrm{M}$ at $-50 \mathrm{mV}$ to $5 \times 10^{-3} \mathrm{M}$ at $+25 \mathrm{mV}$. These changes are consistent with a positively charged ligand binding with higher affinity at negative membrane potentials. This cannot readily explain the voltage-dependent changes in Hill slopes either.

In addition and not mutually exclusive, these observations could indicate that the affinity of the binding site for $\mathrm{Ca}^{2+}$ changes as a function of membrane potential because of a change in the protein conformation. For example, different channel conformations (closed or activated) may have distinct $\mathrm{Ca}^{2+}$ affinities. The data indicate that the resting closed channels bind $\mathrm{Ca}^{2+}$ with a higher affinity than the activated channel. Membrane potential determines the fraction of channels that are in the resting or activated states and the apparent $\mathrm{K}_{\mathrm{D}}$ increases at more depolarized potentials in which more channels are activated.

The voltage dependence of the Hill fits led us to consider an allosteric model for the $\mathrm{Ca}^{2+}$-channel interactions. Many multisubunit proteins including ion channels exhibit cooperativity, and conformational changes that confer differential ligand affinity have been described for many allosteric proteins (Monod et al., 1965; Hille, 1977; Hondeghem and Katzung, 1977; Marks and Jones, 1992; Galzi et al., 1996; Cox et al., 1997; Changeux and Edelstein, 1998; Horrigan and Aldrich, 1999; Rothberg and Magleby, 1999).

\section{Allosteric modulation of gating by $\mathrm{Ca}^{2+}$}

To refine the analysis of the $\mathrm{Ca}^{2+}$-HERG interaction, we considered voltage-dependent allosteric models of channel-gating and $\mathrm{Ca}^{2+}$ interactions. Because HERG is a voltage-gated channel (Sanguinetti et al., 1995; Trudeau et al., 1995), numerous states must be considered to account for channel voltage dependence (Patlak, 1991; Bezanilla et al., 1994; S. Wang et al., 1997). These channels are homotetramers when expressed heterologously. The four-fold symmetry of the channel naturally leads to at least five states to describe channels with $0-4$ voltage sensors activated. Channel inactivation requires additional states. If only a single $\mathrm{Ca}^{2+}$ binds to each homotetrameric channel, then all four subunits must create a single $\mathrm{Ca}^{2+}$ binding site on the extracellular face of the channel. This site would necessarily be centrally located, as with tetraethylammonium (TEA) and certain toxins (Hurst et al., 1992), and would therefore likely be in the channel pore. However, $\mathrm{Ca}^{2+}$ does not block HERG channels (Johnson et al., 1999). The radial symmetry of the channel, the apparent cooperativity seen in the $\mathrm{Ca}^{2+}$ concentration-response curve Hill fits (data not shown), and the unlikelihood of a single central $\mathrm{Ca}^{2+}$ binding site suggest that each subunit has its own $\mathrm{Ca}^{2+}$ site(s). Minimally, to accommodate five voltage-dependent states and five calcium-liganded states requires a 25 state model. To include $\mathrm{Ca}^{2+}$ and voltage dependence and the allosteric changes from closed to activated channel conformations requires at least a two-tiered 50 state allosteric model Rothberg and Magleby, 1999). Nonindependent voltage sensors or $\mathrm{Ca}^{2+}$ binding would lead to even larger models (Horrigan et al., 1999).

As the complexity of these models increases, the number of free parameters increases, and confidence in the meaning of individual parameters decreases. Results shown below and in our previous work (Johnson et al., 1999) indicate that the inactivated states cannot be distinguished from open states with regard to $\mathrm{Ca}^{2+}$; hence, combining open and inactivated states that are occupied during depolarizations can be justified. Because the primary goal of this work was to understand the $\mathrm{Ca}^{2+}$ modulation of HERG, we can further simplify the analysis by combining the voltage sensing steps into a single concerted transition. There is reasonable evidence that in other voltage-gated $\mathrm{K}^{+}$channels (Bezanilla, 2000), $\mathrm{Ca}^{2+}$-activated $\mathrm{K}^{+}$channels (Cox et al., 1997; Horrigan et al., 1999; Rothberg and Magleby, 1999), and $\mathrm{Ca}^{2+}$ channels (Marks and Jones, 1992) a final cooperative step is indeed responsible for channels leaving the closed state.

Assuming four binding sites for the tetrameric channel, there are at least five types of states corresponding to the channel with 0-4 $\mathrm{Ca}^{2+}$ bound. The open to inactivated transitions of HERG are $\mathrm{Ca}^{2+}$ insensitive (Johnson et al., 1999), which permitted us to combine the open and inactivated states (referred to as activated). Making the assumption that only the voltage-dependent conformation of the channel (closed or activated) determines the affinity for $\mathrm{Ca}^{2+}$ and that each subunit binds $\mathrm{Ca}^{2+}$ independently from the others, the degree of $\mathrm{Ca}^{2+}$ binding then biases the fundamental voltage-dependent transition. The result is the simplified two-tiered, 10 state MWC model [see Cox et al. (1997) for in-depth discussion of this approach shown below in scheme 1 and described in Eq. 3] if $\mathrm{Ca}^{2+}$ only distinguishes closed and activated states (i.e., all closed state dissociation constants, $K c$, are equivalent, as are all activated state dissociation constants, $K a$ ). In this model, the receptor (here the HERG channel) protein exists in two possible conformations, tense or relaxed, corresponding in this case to the closed or activated channel (Monod et al., 1965; Changeux and Edelstein, 1998).

This voltage-dependent allosteric model (see Eq. 3) was fit to all of the data simultaneously as a function of the known membrane potentials and $\mathrm{Ca}^{2+}$ concentrations. Figure 6 shows the voltage- and $\mathrm{Ca}^{2+}$-response surface that was fitted to these data sets. The shaded gray bands indicate the height along the vertical axis. Round symbols show the mean data points, and the vertical lines on the symbols show the distance of the data points from the fitted plane, illustrating the quality of the fit.

This simple model fit the observed data remarkably well. The 

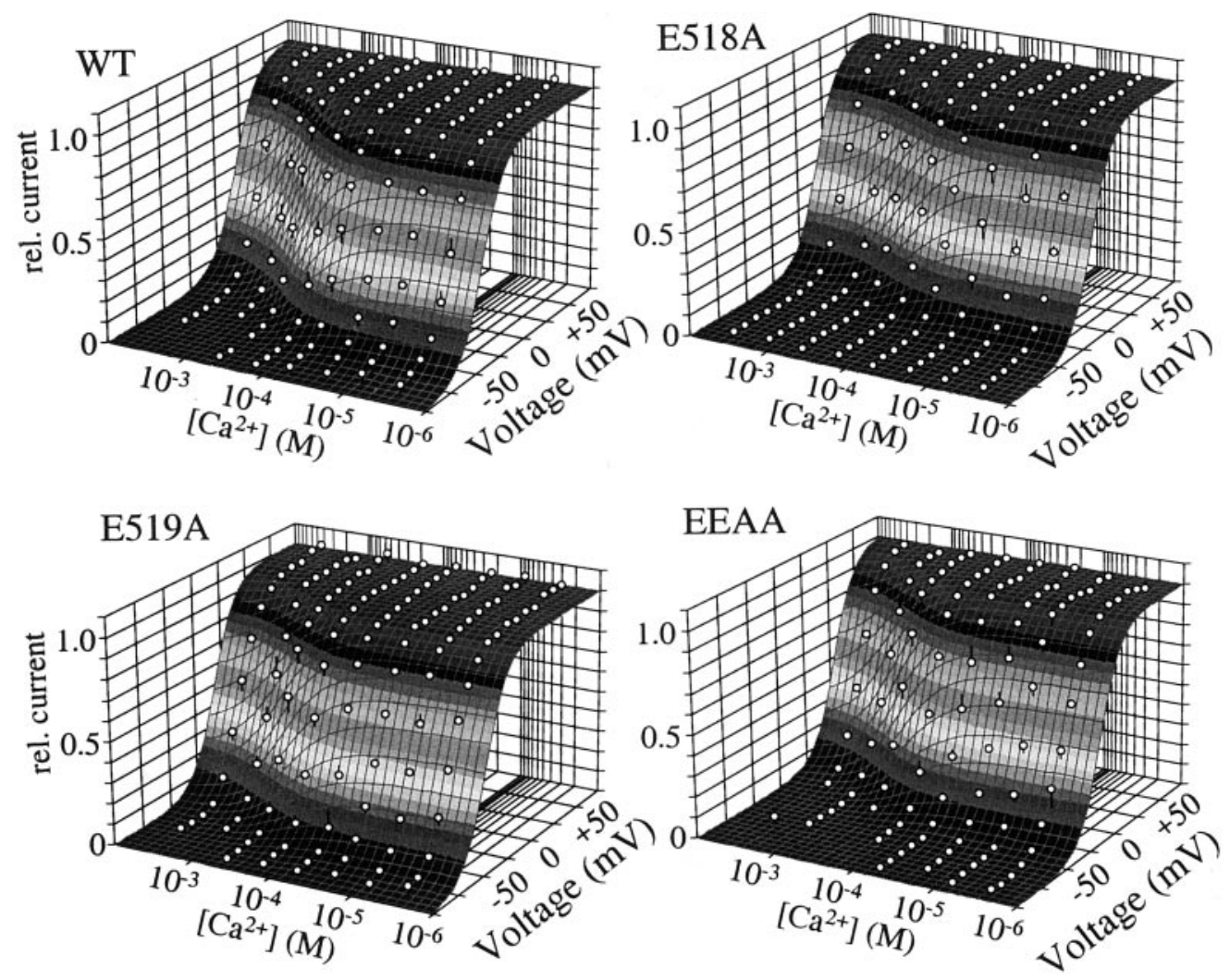

Figure 6. $\mathrm{Ca}^{2+}$-membrane voltage-response surface. Three-dimensional regression fits of the voltage-dependent Monod-Wyman-Changeaux model to relative $\mathrm{K}^{+}$currents for WT and mutant HERG measured in different $\mathrm{Ca}^{2+}$ concentrations and at different membrane potentials. The mean voltageactivation data for all $\mathrm{Ca}^{2+}$ concentrations are plotted as a function of membrane potential in a three-dimensional format. The vertical error bars on the symbols indicate the distance of the mean data point from the fitted plane.

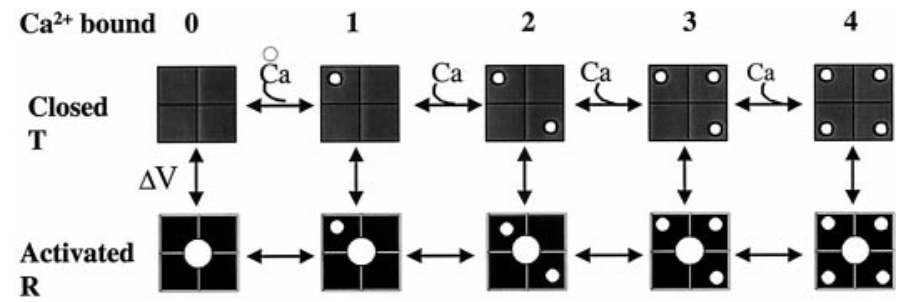

Scheme 1

smooth curves in Figures 4 and 5, as well as the shaded gray surface in Figure 6, are all from the model fit. The fitted parameters are shown in Figure 7. The sensitivity of the channels to changes in membrane potential was similar in all channels and at all $\mathrm{Ca}^{2+}$ concentrations, as reflected by the fitted $Q$ (apparent gating charge), which was the same for all the channels (mean \pm $\mathrm{SE} ; \mathrm{WT}=2.3 \pm 0.05 e^{-}, \mathrm{E} 518 \mathrm{~A}=2.5 \pm 0.04 e^{-}, \mathrm{E} 519 \mathrm{~A}=2.4 \pm$ $\left.0.05 e^{-}, \mathrm{EEAA}=2.5 \pm 0.002 e^{-}\right)$. The constancy of $Q$ among the different channels suggests that the E518 and E519 do not constitute part of the gating charge and are not directly responsible for voltage sensing. The change in free energy required to move the channels from closed to activated states in the absence of $\mathrm{Ca}^{2+}$ and voltage $\left(L_{0}\right)$ differed considerably among the channels. This is apparent not only from fitted $L_{0}$ values (Fig. 7), but also by the increased voltage threshold for channel activation in the E518A and EEAA mutants visible in Figures 4 and 5. In contrast, the E519A mutant had an $L_{0}$ similar to that of the wild-type

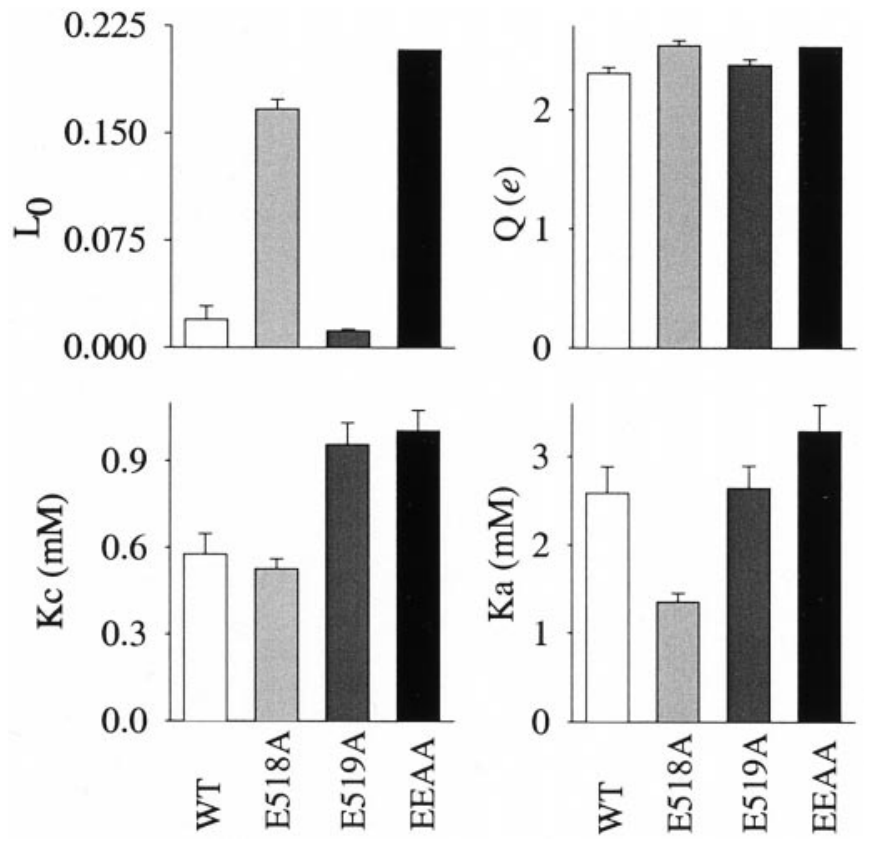

Figure 7. Fitted parameters of the voltage-dependent MWC model for WT and mutant HERGs. $L_{0}$ is the equilibrium constant for the allosteric transition between the closed and activated states in the absence of $\mathrm{Ca}^{2+}$ at $0 \mathrm{mV} . Q$ is the equivalent gating charge in $e^{-} . K c$ is the $\mathrm{Ca}^{2+}$ dissociation constant for the closed channel. $\mathrm{Ka}$ is the $\mathrm{Ca}^{2+}$ dissociation constant for the activated channel. The parameter uncertainties (SDs) are shown as error bars and were determined from the covariance matrix. 
channel. Removal of the negative charge at position 518 had little effect on the $\mathrm{Ca}^{2+}$ dissociation constant of the closed channel (Kc; Fig. 7), but channels bearing an E519A mutation had a $K c$ twice that of the WT or E518A mutant, indicating that neutralization of this negative charge decreased the affinity of the closed channel for $\mathrm{Ca}^{2+}$.

We found that the E518A mutant had a reduced $\mathrm{Ka}$, indicating an enhanced affinity of activated channels for $\mathrm{Ca}^{2+}$, despite the fact that $K a$ was not reduced in the EEAA double mutant. This observation suggests that the 518 and 519 amino acids are not entirely independent with respect to their influence on activated channel $\mathrm{Ca}^{2+}$ binding. To quantify the degree of energetic coupling between these amino acids, we used thermodynamic mutant cycle analysis (see Scheme 1 and Eq. 4) (Carter et al., 1984; Sali et al., 1991; Hidalgo and MacKinnon, 1995; Schreiber and Fersht, 1995; Horovitz, 1996; Ranganathan et al., 1996; Frisch et al., 1997). The distinct $\mathrm{Ca}^{2+}$ dissociation constants for the closed $(K c)$ and activated $(K a)$ states and the equilibrium constant $\left(L_{0}\right)$ for the distribution among closed and activated states for each channel were used to estimate the energetic interactions between these charged amino acids in the different conformational states. Using these parameters, a coupling coefficient $(\boldsymbol{\Omega})$ was calculated (Eq. 4). An $\boldsymbol{\Omega}$ of unity indicates independence and a lack of energetic coupling. Deviations of $\boldsymbol{\Omega}$ from unity indicate energetic coupling between the amino acids. The $\Omega$ values were: $L_{0}, 21.2$; $K c, 1.1 ; K a, 2.4$. The large $\boldsymbol{\Omega}$ for the $L_{0}$ indicates that there is energetic coupling between these amino acids in determining the equilibrium change in free energy between the closed and activated states, although clearly E518 was more critical in determining the $L_{0}$ value (Fig. 7). The coupling coefficient for the closed channel $\mathrm{Ca}^{2+}$ dissociation constant was near unity, indicating a lack of coupling between these residues in the closed states. In contrast, $\boldsymbol{\Omega}$ for activated channels was 2.4 , indicating that an interaction between these amino acids influences $\mathrm{Ca}^{2+}$ binding on channel opening. This $\boldsymbol{\Omega}$ value is relatively small, but it is noteworthy because these adjacent residues did not display coupling in the closed state. This implies a change in the microenvironment around E518 and E519 between the closed and activated channels. The negative charge at position 518 influences $\mathrm{Ca}^{2+}$ association when the channel is in the activated state but not when the channel is closed.

\section{DISCUSSION}

Our data revealed a novel mechanism for extracellular calcium modulation of an important ion channel and indicated that the affinity of HERG channels for $\mathrm{Ca}^{2+}$ is dependent on its conformational state. Significant changes in gating occur with very modest changes in $\left[\mathrm{Ca}^{2+}\right]_{\mathrm{o}}$ because the modulation occurs in the middle of the normal extracellular range of calcium concentrations. This suggests that rather modest fluctuations in $\left[\mathrm{Ca}^{2+}\right]_{\mathrm{o}}$ in clefts or restricted spaces can have marked changes on this repolarizing $\mathrm{K}^{+}$current.

We find that negatively charged amino acids in the S3-S4 linker critically bias normal voltage and $\mathrm{Ca}^{2+}$ dependence of the channel. $\mathrm{Ca}^{2+}$ is well known as an intracellular second messenger, but recently it has also been found to be an important first messenger extracellularly (Brown, 1999). Extracellular $\mathrm{Ca}^{2+}$ receptors are involved in regulation of serum $\mathrm{Ca}^{2+}$. These receptors, like HERG, have millimolar affinity for $\mathrm{Ca}^{2+}$. Even small changes in extracellular $\mathrm{Ca}^{2+}$ can have large effects on HERG current density under conditions resembling those in vivo (Johnson et al., 1999). A low-affinity interaction between $\mathrm{Ca}^{2+}$ and extracellular sites on proteins like HERG and the $\mathrm{Ca}^{2+}$ receptor is mandatory if physiological fluctuations in $\mathrm{Ca}^{2+}$ are to dynamically modify protein function. At normal mammalian serum $\mathrm{Ca}^{2+}$ concentrations of $\sim 1.3 \mathrm{~mm}$ (Brown, 1999), a high-affinity site, like an EF hand motif, would be continuously occupied, preventing modulation.

Our results indicate that the glutamate at position 518 is critical in determining the normal voltage dependence of HERG channels. In contrast, the glutamate at position 519 has little effect on the intrinsic voltage dependence of the channel, but instead is involved in determining the response of the channel to extracellular $\mathrm{Ca}^{2+}$. What is the physical explanation for these effects? The diagram in Figure 8 shows one possibility. Transmembrane domains of a single channel subunit emphasizing the positively charged S4 transmembrane voltage sensor domain are represented. In the diagram, activation of the voltage sensor is shown as a movement of the $\mathrm{S} 4$ as recent studies indicate (Larsson et al., 1996; Cha and Bezanilla, 1997, 1998; Cha et al., 1999; Bezanilla, 2000; Horn, 2000). The negative charge of a glutamate (E518) in the extracellular loop connecting S3 and S4 electrostatically interacts with positive charge(s) of the S4 voltage sensor, encouraging (attracting) the activating motion of the S4. Removing the negative charge at position 518 (E518A mutation) increases the energy required for activation and thus shifts the voltage dependence of activation to more positive potentials. Removing the negative charge at position 518 (E518A mutation) also increases the affinity of the channel for $\mathrm{Ca}^{2+}$ during channel activation (opening) relative to the WT channel, suggesting that the $\mathrm{Ca}^{2+}$ binding motif is better able to associate stably with $\mathrm{Ca}^{2+}$. The negative charge of a glutamate (E519) participates in the association of $\mathrm{Ca}^{2+}$ with the channel protein, and thus the E519A mutation alters the $\mathrm{Ca}^{2+}$ response. A conformational change in the S3-S4 loop during channel activation gating (opening) interferes with the association of $\mathrm{Ca}^{2+}$ with the channel protein, lowering the affinity.

It should be noted that we have no direct proof that either of the two glutamic acid residues that we investigated directly interacts with $\mathrm{Ca}^{2+}$. They may merely influence its effect on the channel, perhaps through the surrounding electrostatic field projected from the protein surface or through other allosteric mechanisms. Our data do show that the actions are fairly specific and that these amino acids are involved. Calcium ions are typically coordinated by multiple negatively charged amino acids, and mutation of one of the coordinate sites is highly disruptive of high-affinity interactions. The interaction seen here is rather low affinity, unlike typical $\mathrm{Ca}^{2+}$ coordination sites, for example in calmodulin, so perhaps there is no such coordination, but simply an electrostatic interaction. This could explain both the lower affinity and the modest disruption caused by the mutations, but it requires other interaction sites.

Interestingly, many peptide toxins also modify voltage-gated ion channels by altering voltage dependence through an association with the S3-S4 extracellular domain. The voltage dependences of $\mathrm{Na}^{+}, \mathrm{Ca}^{2+}$, and $\mathrm{K}^{+}$channel gating are modified by differences in this region or by binding of toxins to the S3-S4 linker domains (Rogers et al., 1996; Dib-Hajj et al., 1997; McDonough et al., 1997; Cestele et al., 1998). Splice variants of $\alpha 1 \mathrm{~A}$ (Bourinet et al., 1999) and $\alpha 1 B$ (Hans et al., 1999; Lin et al., 1999) $\mathrm{Ca}^{2+}$ channel subunits that differ in this region are distinguishable by their altered voltage dependence of gating.

Other $\mathrm{K}^{+}$channels are also sensitive to changes in the extracellular residues near the voltage sensor (Elinder and Århem, 

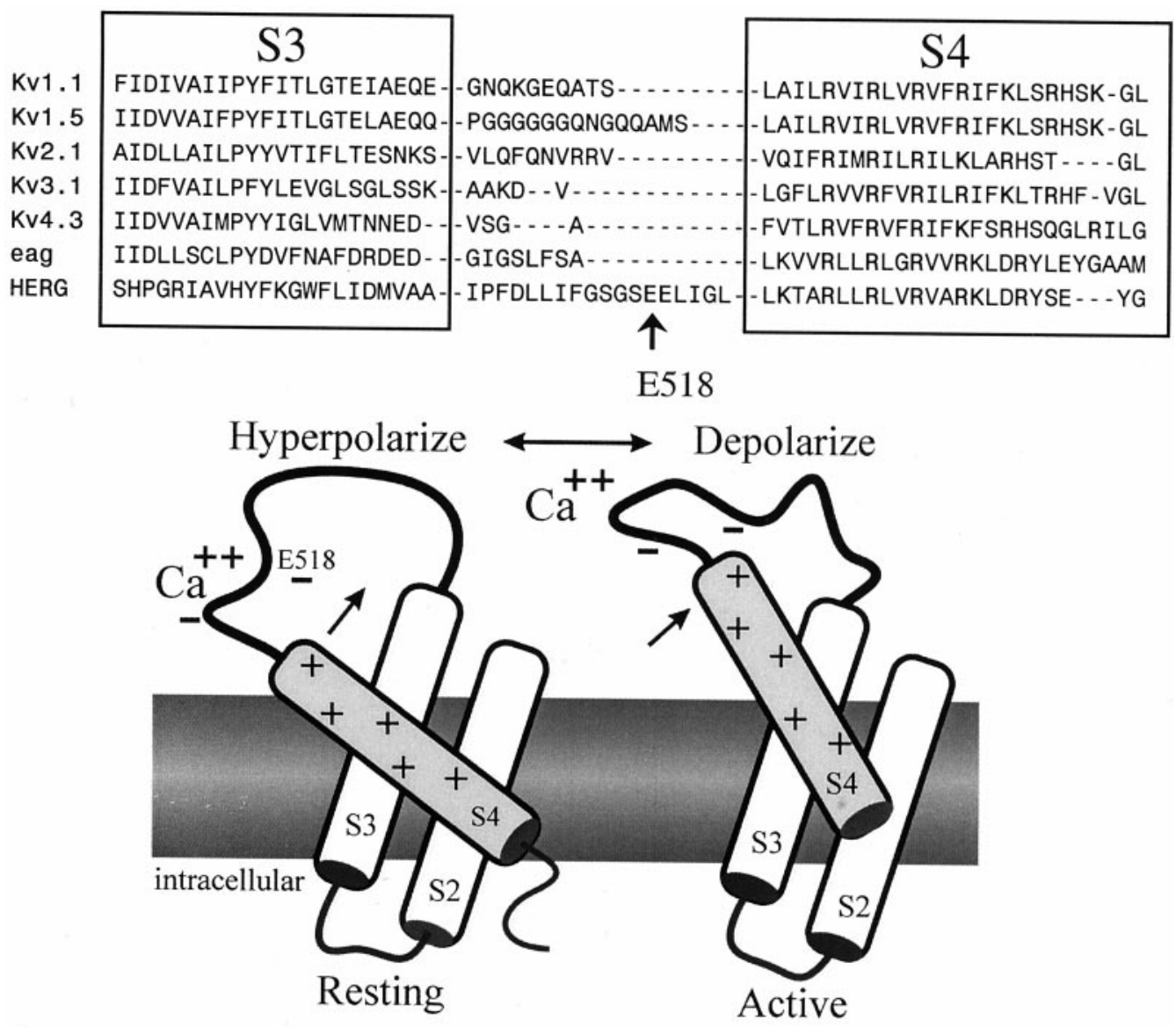

Figure 8. Top, Amino acid alignment of S3-S4 segments of several voltage-gated potassium channels. Standard single letter amino acid abbreviations are used. Glutamate 518 (E518) in HERG is indicated by an arrow. Kv1.1, Kv1.5, Kv2.1, Kv3.1, and Kv4.3 indicate the human channels corresponding to KCNA1, KCNA5, KCNB1, KCNC1, and KCND3, respectively. eag is Drosophila ether-à-go-go, and HERG corresponds to KCNH2. Bottom, Diagram of a plausible physical explanation for the interactions between negative charges in $\mathrm{S} 3-\mathrm{S} 4$, positive charges in $\mathrm{S} 4$, and extracellular $\mathrm{Ca}^{2+}$. $\mathrm{Ca}^{2+}$ interacts at the surface of the channel at a site near the S4 voltage sensor by attraction to the negative charge of glutamate 519. The data suggest that E519 may participate in the $\mathrm{Ca}^{2+}$ binding site. The negative charge of glutamate 518 (E518) attracts or stabilizes positive charges in S4 and promotes or facilitates channel opening. Thus, E518 affects the $\mathrm{Ca}^{2+}$-independent voltage-dependence of the channel by electrostatic interaction with the voltage sensor. Adapted from Papazian and Bezanilla (1999) for HERG channels.

1999). Tang et al. (2000) characterized the effects of $\mathrm{Mg}^{2+}$ on Drosophila ether-à-go-go $\mathrm{K}^{+}$channel (eag). They found that $\mathrm{Mg}^{2+}$ slowed activation eag-gating kinetics. Splice variants of bovine eag that differ in the length of the S3-S4 loop show distinct $\mathrm{Mg}^{2+}$ sensitivities (Frings et al., 1998). Drosophila eag contains a DRED (Asp-Arg-Glu-Asp) motif at amino acids 333337 at the C-terminal end of S3. Tang et al. (2000) deleted these charged amino acids and found a depolarizing shift in the voltage-activation curves consistent with removal of a negative surface charge, but gating was still modified by $\mathrm{Mg}^{2+}$. They concluded that the DRED sequence does not constitute an $\mathrm{Mg}^{2+}$ binding site. HERG channels do not possess DRED amino acids at analogous positions. Interestingly, mutation of leucine at position 342 to histidine $(\mathrm{L} 342 \mathrm{H})$ in S3-S4 eliminated the modulation by $\mathrm{Mg}^{2+}$. It is unlikely that leucine is directly involved in $\mathrm{Mg}^{2+}$ binding, although a mutation at this position may perturb $\mathrm{Mg}^{2+}$ binding or the coupling of the $\mathrm{Mg}^{2+}$ effect to the voltage sensor. Alternatively, addition of a charged histidine may prevent access to an $\mathrm{Mg}^{2+}$ site by introduction of a local positive charge. More recently, Silverman et al. (2000) provided evidence that aspartic acids at positions 278 and 327 in eag constitute an $\mathrm{Mg}^{2+}$ binding site. Mutations of these negatively charged amino acids to ala- nines greatly altered the response to $\mathrm{Mg}^{2+}$, although no concentration dependence was defined. As such it is not possible to compare the binding affinities or energetics. The composition of the S3-S4 linker affects the voltage sensitivity of Shaker $\mathrm{K}^{+}$ channel gating (Mathur et al., 1997), and natural toxins affect $\mathrm{K}^{+}$ channel gating by binding near this site (Swartz and MacKinnon, 1997a,b), all consistent with our observations on HERG channels that S3-S4 is a critical modulatory domain. Together, these observations of interactions between extracellular effectors and channel S3-S4 regions near the voltage sensor reveal the general importance of this key modulatory domain (Li-Smerin and Swartz, 1998; Winterfield and Swartz, 2000).

We conclude that extracellular $\mathrm{Ca}^{2+}$ is an allosteric modulator of the HERG K ${ }^{+}$channel. $\mathrm{Ca}^{2+}$ associates with closed channels (occupied at negative membrane potentials) with higher affinity than with activated channels (occupied at less negative membrane potentials), thereby stabilizing the closed state. Two glutamates in the S3-S4 linker domain, E518 and E519, are critical for normal HERG function. Neutralization of E518 shifts the voltage dependence of channel opening to more depolarized membrane potentials promoting closed states, possibly by removing a negative charge that is normally attracting the S4 positive charge. 
Neutralization of E518 does not affect the affinity of the closed channel for $\mathrm{Ca}^{2+}$. Neutralization of E519 does not appear to affect the membrane potential sensed by the voltage sensor but does decrease the affinity of the closed channel for $\mathrm{Ca}^{2+}$. The E518 and E519 residues are energetically coupled in the activated channel but not in the closed channel. These results emphasize the importance of the S3-S4 linker in channel function and present a mechanism of $\mathrm{Ca}^{2+}$ action on this physiologically important ion channel.

\section{REFERENCES}

Arcangeli A, Rosati B, Cherubini A, Crociani O, Fontana L, Ziller C, Wanke E, Olivotto M (1997) HERG- and IRK-like inward rectifier currents are sequentially expressed during neuronal development of neural crest cells and their derivatives. Eur J Neurosci 9:2596-2604.

Balser JR, Roden DM, Bennett PB (1990) Global parameter optimization for cardiac potassium channel gating models. Biophys $\mathbf{J}$ $57: 433-444$.

Bezanilla F (2000) The voltage sensor in voltage-dependent ion channels. Physiol Rev 80:555-592.

Bezanilla F, Perozo E, Stefani E (1994) Gating of Shaker K+ channels: II. The components of gating currents and a model of channel activation. Biophys J 66:1011-1021.

Bianchi L, Wible B, Arcangeli A, Taglialatela M, Morra F, Castaldo P, Crociani O, Rosati B, Faravelli L, Olivotto M, Wanke E (1998) Herg encodes a K+ current highly conserved in tumors of different histogenesis: a selective advantage for cancer cells. Cancer Res 58:815-822.

Bourinet E, Soong TW, Sutton K, Slaymaker S, Mathews E, Monteil A, Zamponi GW, Nargeot J, Snutch TP (1999) Splicing of alpha 1A subunit gene generates phenotypic variants of P- and Q-type calcium channels. Nat Neurosci 2:407-415.

Brown EM (1999) Physiology and pathophysiology of the extracellular calcium-sensing receptor. Am J Med 106:238-253.

Carter PJ, Winter G, Wilkinson AJ, Fersht AR (1984) The use of double mutants to detect structural changes in the active site of the tyrosyl-tRNA synthetase (Bacillus stearothermophilus). Cell 38:835-840.

Cestele S, Qu Y, Rogers JC, Rochat H, Scheuer T, Catterall WA (1998) Voltage sensor-trapping: enhanced activation of sodium channels by beta-scorpion toxin bound to the S3-S4 loop in domain II. Neuron 21:919-931.

Cha A, Bezanilla F (1997) Characterizing voltage-dependent conformational changes in the Shaker K+ channel with fluorescence. Neuron 19:1127-1140.

Cha A, Bezanilla F (1998) Structural implications of fluorescence quenching in the Shaker K+ channel. J Gen Physiol 112:391-408.

Cha A, Snyder GE, Selvin PR, Bezanilla F (1999) Atomic scale movement of the voltage-sensing region in a potassium channel measured via spectroscopy. Nature 402:809-813.

Changeux JP, Edelstein SJ (1998) Allosteric receptors after 30 years. Neuron 21:959-980.

Chiesa N, Rosati B, Arcangeli A, Olivotto M, Wanke E (1997) A novel role for HERG K+ channels: spike-frequency adaptation. J Physiol (Lond) [Erratum (1997) 502:715] 501:313-318.

Cowan JA (1993) Inorganic biochemistry: an introduction. New York: $\mathrm{VCH}$

Cox DH, Cui J, Aldrich RW (1997) Allosteric gating of a large conductance Ca-activated K+ channel. J Gen Physiol 110:257-281.

Dib-Hajj SD, Ishikawa K, Cummins TR, Waxman SG (1997) Insertion of a SNS-specific tetrapeptide in S3-S4 linker of D4 accelerates recovery from inactivation of skeletal muscle voltage-gated Na channel mu1 in HEK293 cells. FEBS Lett 416:11-14.

Eismann E, Muller F, Heinemann SH, Kaupp UB (1994) A single negative charge within the pore region of a cGMP-gated channel controls rectification, $\mathrm{Ca} 2+$ blockage, and ionic selectivity. Proc Natl Acad Sci USA 91:1109-1113.

Elinder F, Arhem P (1999) Role of individual surface charges of voltagegated K channels. Biophys J 77:1358-1362.

Frankenhaeuser B, Hodgkin AL (1957) The action of calcium on the electrical properties of squid axons. J Physiol (Lond) 137:218-244.

Frings S, Brull N, Dzeja C, Angele A, Hagen V, Kaupp UB, Baumann A (1998) Characterization of ether-a-go-go channels present in photoreceptors reveals similarity to $\mathrm{IKx}$, a $\mathrm{K}+$ current in rod inner segments. J Gen Physiol 111:583-599.

Frisch C, Schreiber G, Johnson CM, Fersht AR (1997) Thermodynamics of the interaction of barnase and barstar: changes in free energy versus changes in enthalpy on mutation. J Mol Biol 267:696-706.

Galzi JL, Edelstein SJ, Changeux JP (1996) The multiple phenotypes of allosteric receptor mutants. Proc Natl Acad Sci USA 93:1853-1858.

Gilly WF, Armstrong CM (1982) Divalent cations and the activation kinetics of potassium channels in squid giant axons. J Gen Physiol 79:965-996.

Hans M, Urrutia A, Deal C, Brust PF, Stauderman K, Ellis SB, Harpold MM, Johnson EC, Williams ME (1999) Structural elements in domain IV that influence biophysical and pharmacological properties of human alpha1A-containing high-voltage-activated calcium channels. Biophys J 76:1384-1400.

Hidalgo P, MacKinnon R (1995) Revealing the architecture of a K+ channel pore through mutant cycles with a peptide inhibitor. Science 268:307-310.

Hille B (1977) Local anesthetics: hydrophilic and hydrophobic pathways for the drug-receptor reaction. J Gen Physiol 69:497-515.

Ho WK, Kim I, Lee CO, Earm YE (1998) Voltage-dependent blockade of HERG channels expressed in Xenopus oocytes by external Ca2+ and $\mathrm{Mg} 2+$. J Physiol (Lond) 507:631-638.

Hondeghem LM, Katzung BG (1977) Time- and voltage-dependent interactions of antiarrhythmic drugs with cardiac sodium channels. Biochim Biophys Acta 472:373-398.

Horn R (2000) A new twist in the saga of charge movement in voltagedependent ion channels. Neuron 25:511-514.

Horovitz A (1996) Double-mutant cycles: a powerful tool for analyzing protein structure and function. Fold Des 1:R121-R126.

Horrigan FT, Aldrich RW (1999) Allosteric voltage gating of potassium channels II: Mslo channel gating charge movement in the absence of $\mathrm{Ca} 2+$. J Gen Physiol 114:305-336.

Hurst RS, Kavanaugh MP, Yakel J, Adelman JP, North RA (1992) Cooperative interactions among subunits of a voltage-dependent potassium channel. Evidence from expression of concatenated cDNAs. J Biol Chem 267:23742-23745.

Johnson JPJ, Mullins FM, Bennett PB (1999) Human ether-a-go-gorelated gene $\mathrm{K}+$ channel gating probed with extracellular $\mathrm{Ca} 2+$. Evidence for two distinct voltage sensors. J Gen Physiol 113:565-580.

Jurman ME, Boland LM, Liu Y, Yellen G (1994) Visual identification of individual transfected cells for electrophysiology using antibody-coated beads. Biotechniques 17:876-881.

Larsson HP, Baker OS, Dhillon DS, Isacoff EY (1996) Transmembrane movement of the shaker K+ channel S4. Neuron 16:387-397.

Lin Z, Lin Y, Schorge S, Pan JQ, Beierlein M, Lipscombe (1999) Alternative splicing of a short cassette exon in alpha1B generates functionally distinct $\mathrm{N}$-type calcium channels in central and peripheral neurons. J Neurosci 19:5322-5331.

Li-Smerin Y, Swartz KJ (1998) Gating modifier toxins reveal a conserved structural motif in voltage-gated $\mathrm{Ca} 2+$ and $\mathrm{K}+$ channels. Proc Natl Acad Sci USA 95:8585-8589.

Mannuzzu LM, Moronne MM, Isacoff EY (1996) Direct physical measure of conformational rearrangement underlying potassium channel gating. Science 271:213-216.

Marks TN, Jones SW (1992) Calcium currents in the A7r5 smooth muscle-derived cell line. An allosteric model for calcium channel activation and dihydropyridine agonist action. J Gen Physiol 99:367-390.

Mathur R, Zheng J, Yan Y, Sigworth FJ (1997) Role of the S3-S4 linker in Shaker potassium channel activation. J Gen Physiol 109:191-199.

McDonough SI, Lampe RA, Keith RA, Bean BP (1997) Voltagedependent inhibition of $\mathrm{N}$ - and P-type calcium channels by the peptide toxin omega-grammotoxin-SIA. Mol Pharmacol 52:1095-1104.

Monod J, Wyman J, Changeux JP (1965) On the nature of allosteric transitions: a plausible model. J Mol Biol 12:88-1181.

Papazian DM, Bezanilla F (1999) Voltage-dependent activation of ion channels. Adv Neurol 79:481-491.

Papazian DM, Schwarz TL, Tempel BL, Jan YN, Jan LY (1987) Cloning of genomic and complementary DNA from Shaker, a putative potassium channel gene from Drosophila. Science 237:749-753.

Patlak J (1991) Molecular kinetics of voltage-dependent Na+ channels. Physiol Rev 71:1047-1080.

Perozo E, Santacruz-Toloza L, Stefani E, Bezanilla F, Papazian DM (1994) S4 mutations alter gating currents of Shaker K channels. Biophys J 66:345-354.

Po SS, Wang DW, Yang IC, Johnson Jr JP, Nie L, Bennett PB (1999) Modulation of HERG potassium channels by extracellular magnesium and quinidine. J Cardiovasc Pharmacol 33:181-185.

Ranganathan R, Lewis JH, MacKinnon R (1996) Spatial localization of the $\mathrm{K}+$ channel selectivity filter by mutant cycle-based structure analysis. Neuron 16:131-139.

Rogers JC, Qu Y, Tanada TN, Scheuer T, Catterall WA (1996) Molecular determinants of high affinity binding of alpha-scorpion toxin and sea anemone toxin in the S3-S4 extracellular loop in domain IV of the $\mathrm{Na}+$ channel alpha subunit. J Biol Chem 271:15950-15962.

Rothberg BS, Magleby KL (1999) Gating kinetics of single largeconductance $\mathrm{Ca} 2+$-activated $\mathrm{K}+$ channels in high $\mathrm{Ca} 2+$ suggest a two-tiered allosteric gating mechanism. J Gen Physiol 114:93-124.

Sali D, Bycroft M, Fersht AR (1991) Surface electrostatic interactions contribute little of stability of barnase. J Mol Biol 220:779-788.

Sanguinetti MC, Jiang C, Curran ME, Keating MT (1995) A mechanistic link between an inherited and an acquired cardiac arrhythmia: HERG encodes the IKr potassium channel. Cell 81:299-307. 
Schönherr R, Heinemann SH (1996) Molecular determinants for activation and inactivation of HERG, a human inward rectifier potassium channel. J Physiol (Lond) 493:635-642.

Schreiber G, Fersht AR (1995) Energetics of protein-protein interactions: analysis of the barnase-barstar interface by single mutations and double mutant cycles. J Mol Biol 248:478-486.

Schreiber M, Salkoff L (1997) A novel calcium-sensing domain in the BK channel. Biophys J 73:1355-1363.

Silverman WR, Tang CY, Mock AF, Huh KB, Papazian DM (2000) $\mathrm{Mg} 2+$ modulates voltage-dependent activation in ether-a-go-go potassium channels by binding between transmembrane segments S2 and S3. J Gen Physiol 116:663-678.

Smith PL, Baukrowitz T, Yellen G (1996) The inward rectification mechanism of the HERG cardiac potassium channel. Nature 379:833-836.

Spector PS, Curran ME, Zou A, Keating MT, Sanguinetti MC (1996) Fast inactivation causes rectification of the IKr channel. J Gen Physiol 107:611-619.

Swartz KJ, MacKinnon R (1995) An inhibitor of the Kv2.1 potassium channel isolated from the venom of a Chilean tarantula. Neuron 15:941-949.

Swartz KJ, MacKinnon R (1997a) Hanatoxin modifies the gating of a voltage-dependent $\mathrm{K}+$ channel through multiple binding sites. Neuron 18:665-673.

Swartz KJ, MacKinnon R (1997b) Mapping the receptor site for hanatoxin, a gating modifier of voltage-dependent $\mathrm{K}+$ channels. Neuron 18:675-682.

Tang CY, Bezanilla F, Papazian DM (2000) Extracellular Mg2+ modulates slow gating transitions and the opening of Drosophila ether-ago-go potassium channels. J Gen Physiol 115:319-338.

Tempel BL, Papazian DM, Schwarz TL, Jan YN, Jan LY (1987) Se- quence of a probable potassium channel component encoded at Shaker locus of Drosophila. Science 237:770-775.

Titus SA, Warmke JW, Ganetzky B (1997) The Drosophila erg K+ channel polypeptide is encoded by the seizure locus. J Neurosci 17:875-881.

Trudeau MC, Warmke JW, Ganetzky B, Robertson GA (1995) HERG, a human inward rectifier in the voltage-gated potassium channel family. Science 269:92-95.

Wang J, Trudeau MC, Zappia AM, Robertson GA (1998) Regulation of deactivation by an amino terminal domain in human ether-a-go-gorelated gene potassium channels. J Gen Physiol 112:637-647.

Wang S, Morales MJ, Liu S, Strauss HC, Rasmusson RL (1996) Time, voltage and ionic concentration dependence of rectification of h-erg expressed in Xenopus oocytes. FEBS Lett 389:167-173.

Wang S, Liu S, Morales MJ, Strauss HC, Rasmusson RL (1997) A quantitative analysis of the activation and inactivation kinetics of HERG expressed in Xenopus oocytes. J Physiol (Lond) 502:45-60.

Wang XJ, Reynolds ER, Deak P, Hall LM (1997) The seizure locus encodes the Drosophila homolog of the HERG potassium channel. J Neurosci 17:882-890.

Warmke JW, Ganetzky B (1994) A family of potassium channel genes related to eag in Drosophila and mammals. Proc Natl Acad Sci USA 91:3438-3442.

Winterfield JR, Swartz KJ (2000) A hot spot for the interaction of gating modifier toxins with voltage-dependent ion channels. J Gen Physiol 116:637-644.

Zou A, Xu QP, Sanguinetti MC (1998) A mutation in the pore region of HERG K+ channels expressed in Xenopus oocytes reduces rectification by shifting the voltage dependence of inactivation. J Physiol (Lond) 509:129-137. 